Research Article

\title{
Free vibration Analyses of cracked Laminate Cylindrical Shells made with FRP Composites
}

\author{
R. R. Das $\dot{A}^{*}$, A. Chakraborty ${ }^{\dot{A}}$, A. Guchhait ${ }^{\dot{A}}$ and A. Singla $\dot{A}$ \\ ${ }^{\dot{A}}$ School of Mechanical Engineering, Kalinga Institute of Industrial Technology (KIIT) - University, Odisha, India \\ Accepted 10 January 2014, Available online 01 February 2014, Special Issue-2, (February 2014)
}

\begin{abstract}
Three dimensional finite element analyses of laminated FRP composite made cylindrical shell structures along with interlaminar through-the-thickness cracks have been carried out. The developed FEM based modelling and simulation technique has been yielding results in close agreement with literature. Interlaminar cracks of similar sizes have been considered at edge and internal locations in order to study their effect on natural frequency of vibration of the cantilevered cylindrical composite shell structure. Cracks have been simulated in different locations from the clamped towards the free edge in order to study their effect on free vibration of the laminated shell structure. Interlaminar cracks have been observed to be reducing the natural frequency of vibration of the shell structures to a great extent, hence affecting the stiffness of the structure. However, for similar damage size and locations, internally-cracked composite cylindrical shells are comparatively stiffer than the edge-cracked cylindrical shell structures. Both the edge and internal cracks have been seen to be affecting the stiffness of the shell structure to a great extent through reducing the frequency of vibration, as they are close to the clamped edge. Composite shell structures with cracks towards the free edge have been comparatively safe as they marginally affect the frequency of vibration.
\end{abstract}

Keywords: Cylindrical shell structure, FEM, Laminated FRP composite, Free vibration, Interlaminar cracks. Natural frequency of vibration.

\section{Introduction}

Laminated Fibre Reinforced Polymer (FRP) composite made thin shell structures find tremendous applications in aerospace, marine, civil, transportation and other fields of engineering because of their excellently high specific strength and stiffness properties. Cantilevered cylindrical shells are very common structures in civil engineering and have been used since decades as roofing units for covering larger column-free loads. In addition to that, these shells are easy to fabricate being developable surfaces. In order to exploit the fullest potential of these composite shell forms, an in depth study of their structural behavior is highly essential. There are several aspects of composite shell behavior such as buckling, bending, impact, vibration etc. The present analyses is however restricted only to the undamped free vibration of laminated FRP composite made cylindrical shell structures both in presence and absence of cracks.

The dynamic behavior of cylindrical shell forms have been investigated by several researchers since last two decades. Exact solutions to the moderately thick laminated shells with simply supported boundary conditions can be obtained through an extension of the Sanders shell theory (Reddy, 1984). Free vibration of clamped and simply supported cylindrical shells can be performed by using an

*Corresponding author: R. R. Das

DOI: http://dx.doi.org/10.14741/ijcet/spl.2.2014.117 isoprarmetric doubly curved shear flexible element (Chandrasekhar, 1989). Free vibration of completely free shallow shells can be studied through Ritz method through assuming algebraic polynomial displacement functions (Qatu and Leissa, 1991). A refined shear deformable element can be used to analyze the free vibration of complete circular cylindrical shells for simply supported boundary conditions (Soldatos, 1991). Free vibration of complete circular cylindrical shells for different boundary conditions such as free, simply supported, and clamped could be studied using the Donell shell deformation theory (Nosier and Reddy, 1992). Method of matched asymptotic expansions can be employed to obtain the natural frequencies of complete circular cylindrical shells with free and fixed end boundary conditions (Williams, 1992). The geometrically non-linear vibrations of circular cylindrical shells made with laminated FRP composites can be studied through Ambii-Reddy higher order shear deformation theory. In this approach the equation of motion can be obtained through energy based approach using Lagrange equations capable of retaining the modal damping effects (Ambii, 2011). The Ambii-Reddy higher order shear deformation theory can also be used to investigate the skewed modes in geometrically non-linear vibration of laminated circular cylindrical shells (Ambii, 2012). An improved Fourier series method can be employed to obtain the exact solutions for the free 
vibration of cylindrical shells with elastic boundary conditions (Chen et. al., 2013). In this approach the three displacements of the shell has been represented by a Fourier series with supplement of additional terms introduced to ensure and enhance the convergence of the series of expansions.

Despite the advantages, brittleness of fibres in the composite shell structures is a serious problem. It can manifest itself in easy cracking across the fibres and even easier cracking between the fibres. Because of differences in material properties across the interface of the bonded adjacent layers and presence of gradients in the in-plane stresses, cracks may appear in the composite shell structures. The presence and growth of these damages may significantly affect the structural reliability and durability of the composite shell structures. Although all the previous literatures helped significantly to understand the structural response of these structures, failure analysis of laminated FRP composite made shell structures is still a matter of controversy with respect to a unified design approach. A strain based Finite Element Method (FEM) can be used to analyze the cracked cylindrical shells (Assan and Aliabadi, 1993). Free vibration of doubly and singly patched cracked laminates can be investigated through an assumed hybrid-stress finite element model incorporating two types of modified composite multilayer elements (Yang and Chen, 1996). FEM based dynamic stability behavior of cracked cylindrical shells can be studied. Effect of static load factor, crack orientation on the structural stability can be investigated through this (Javidruzi et al., 2004). Instability of cracked cylindrical shells reinforced by elastic liner can be investigated using a linear eigenvalue analyses (Kim et al., 2013). Instability of the cracked cylindrical shells under combined loading can also be carried out (Allahbakhsh and Shariati, 2014).

The present research is devoted to develop FEM based modelling and simulation techniques facilitating dynamic response analysis of different laminated shell structures in general and a FRP composite made cylindrical shell structures in particular. The developed model is capable of studying the effect of different boundary conditions on the natural frequency of vibration of composite shell structures. In addition to that, dynamic response of composite shell structures in presence of different damages like interlaminar cracks can also suitably be dealt through the developed model.

\section{Specimen geometry and boundary conditions}

The material composition has been considered to be graphite/epoxy ( $\mathrm{Gr} / \mathrm{E})$ laminated FRP composite with a symmetric ply configuration $\left[0^{\circ} / 90^{\circ} / 0^{0}\right]$ (Qatu and Leissa, 1991). The composite cylindrical shell is identical with respect to dimensions (length $(a)=$ breadth $(\mathrm{b})=5000$ $\mathrm{mm}, a / \mathrm{b}=1)$. A thickness (h) of $50 \mathrm{~mm}$, and radius of curvature $\left(\mathrm{R}_{\mathrm{yy}}\right)$ of $10,000 \mathrm{~mm}$ has been adopted such that $\mathrm{b} / \mathrm{h}=100, \mathrm{~b} / \mathrm{R}_{\mathrm{yy}}=0.5$ (Qatu and Leissa, 1991). The upper surface of the cantilevered composite cylindrical shell has been subjected to uniformly distributed loading equivalent to an intensity of $100 \mathrm{~N}$. Density of the shell structure under consideration have been considered to be, $\rho=(1.5 \mathrm{x}$
$10^{-6} \mathrm{~kg} / \mathrm{m}^{3}$ ). The material properties for the orthotropic FRP composite made cylindrical shell have been given in Table 1 .

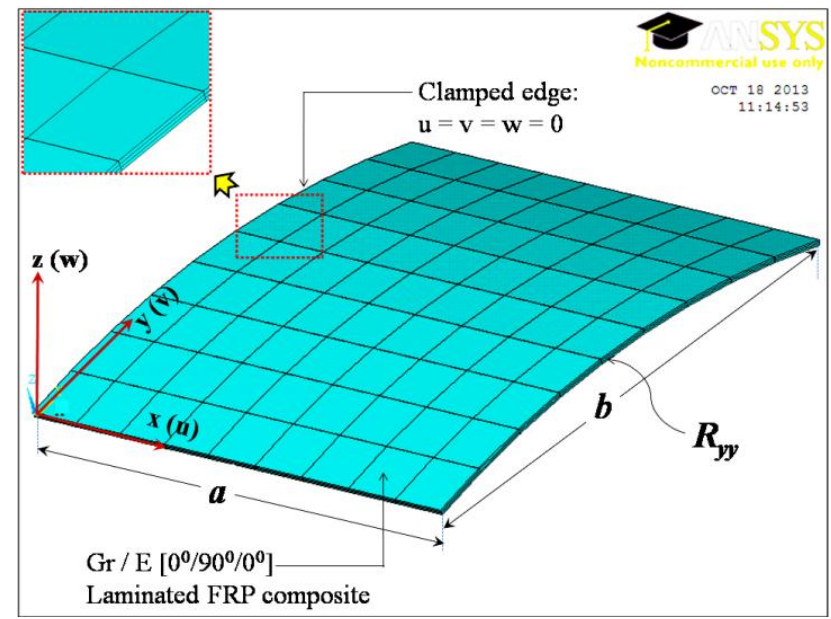

Fig.1 Specimen geometry and boundary conditions of the laminated FRP composite made cantilevered cylindrical shell along with finite element mesh.

Appropriate restrained boundary conditions have been considered for simulating pure cantilevered end conditions for the composite cylindrical shell. These are as follows:

- $\mathrm{u}=\mathrm{v}=\mathrm{w}=0$, for all nodes along $\mathrm{x}=0$; i.e. at the clamped edge of the laminated composite cylindrical shell

where, $\mathrm{u}, \mathrm{v}$ and $\mathrm{w}$ represent the displacements associated with $\mathrm{x}, \mathrm{y}$ and $\mathrm{z}$ coordinates, respectively.

Table 1 Material properties of Gr/E laminated FRP composite used for the cylindrical shell (Qatu and Leissa, 1991).

\begin{tabular}{|l|l|}
\hline Material Composition & Material Constants \\
\hline & $E_{x}=138 \mathrm{GPa}, E_{y}=8.9 \mathrm{GPa}$ \\
Graphite/epoxy & $E_{z}=4.8 \mathrm{GPa}$ \\
laminated FRP composite & $v_{x y}=0.28, v_{y z}=0.41$, \\
& $v_{x z}=0.28$ \\
& $\mathrm{G}_{\mathrm{xy}}=7.1 \mathrm{Gpa}, G_{x z}=4.8$ \\
& $\mathrm{GPa}$ \\
& $G_{y z}=2.55 \mathrm{GPa}$ \\
\hline
\end{tabular}

\section{Finite element modelling}

For modal analyses, the laminated FRP composite made cylindrical shells have been modelled with 4-node SOLID 181 elements with layer-wise prescription of material properties within it. It is a four-node element with six degrees of freedom at each node: translations in the $x, y$, and $\mathrm{z}$ directions, and rotations about the $\mathrm{x}, \mathrm{y}$, and $\mathrm{z}$-axes. ANSYS 14.0 on a high speed IBM platform has been used in order to carry out the FE analysis. Results generated through the presently developed finite element model have been seen to be in close agreement with literature (Qatu and Leissa, 1991). A 9 × 9 mesh has been adopted in the present simulation. The comparison has been represented in Table 2. 
Table 2 Non-dimensional fundamental frequencies (Qatu and Leissa, 1991) of cantilevered laminated composite shells.

\begin{tabular}{|l|l|l|}
\hline Shell Type & $\begin{array}{l}\text { Qatu and Leissa, } \\
1991\end{array}$ & $\begin{array}{l}\text { Present } \\
\text { approach }\end{array}$ \\
\hline $\begin{array}{l}\text { Cantilevered } \\
\text { cylindrical shell }\end{array}$ & 1.8652 & 1.8179 \\
\hline $\begin{array}{l}\text { Cantilevered spherical } \\
\text { shell }\end{array}$ & 1.5362 & 1.5014 \\
\hline
\end{tabular}

In order to analyze the effect of cracks on the fundamental frequency of vibration of the cantilevered composite shells, through-the-thickness cracks of similar sizes have been simulated at the edges and internal locations. Plane of both the edge and internal cracks have been assumed to be parallel to the yz plane as shown in Figure 2 and Figure 3. Hence, their positions have been specified through the distance of the crack center from the clamped edge $\left(\mathrm{x}_{\mathrm{c}}\right)$. The positional coordinates of the edge and internal cracks considered in the present analyses are: edge crack $\left(\mathrm{x}_{\mathrm{c}}\right.$, $4727.21 \mathrm{~mm}, 66.364 \mathrm{~mm})$, internal crack $\left(\mathrm{x}_{\mathrm{c}}, 3341.272\right.$ $\mathrm{mm}, 282.092 \mathrm{~mm}$ ). This indicates that the internal cracks considered are a bit eccentric as they do not lie on the plane of symmetry of the cylindrical shell. However, the edge cracks lie on the edge of the cylindrical shell at $y=b$. In order to study the effect of change of crack position on the fundamental frequency of vibration, different cracks have been simulated through selecting different values of " $\mathrm{x}_{\mathrm{c}}$ ". The crack positions have been considered from the clamped to the free edge of the shell during the course of the present finite element analyses.

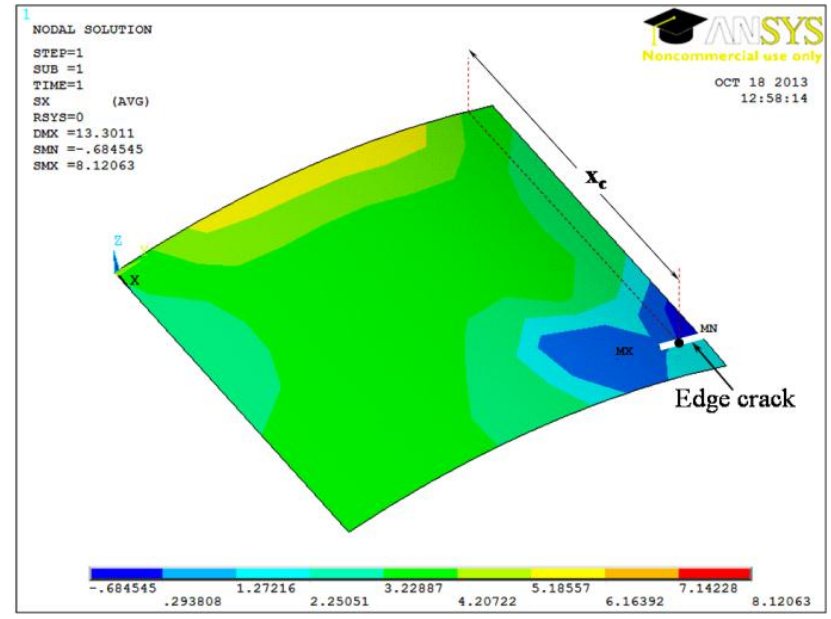

Fig.2 Laminated FRP composite made cylindrical shell with simulated edge cracks.

FE based analyses of crack propagation characteristics in composite shell structures are quite complex. Hence, the FE analysis should incorporate rigorous error analysis procedures and convergence requirements with judicious mesh grading and appropriate element size in the vicinity of the crack front. This is needed to avoid the oscillatory nature of the stress field very near to the damage (Rice, 1988). This has been duly carried out during computational stages to achieve the required level of accuracy. Duplicate nodes have been defined in order to simulate the through-the-thickness edge and internal cracks. In the undelaminated region, corresponding nodes of the sublaminates are constrained by using non-linear Multi Point Constraint (MPC 184) elements so that the continuity condition prevails. Contact elements (CONTA 178) have been used within the cracked region to prevent mutual interpenetration of the delaminated surfaces.

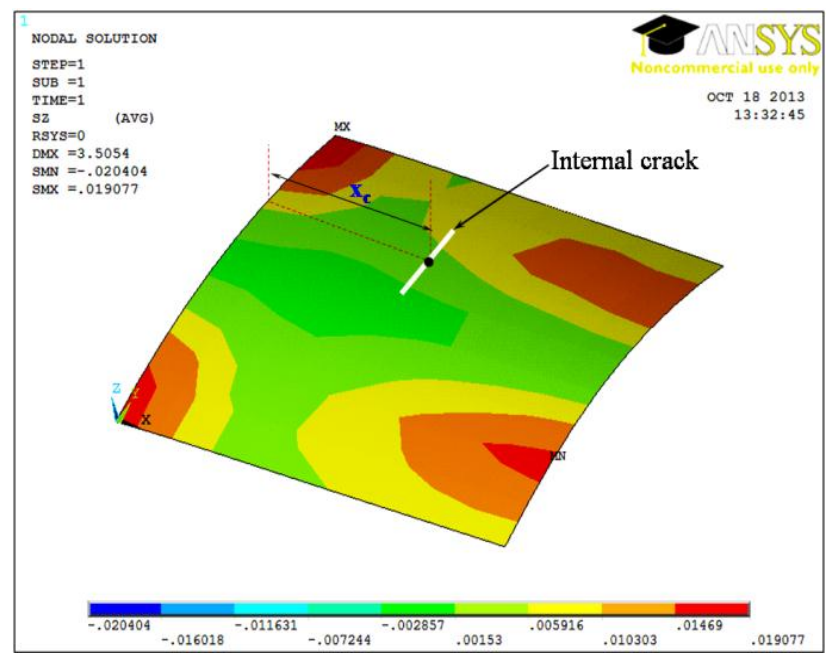

Fig.3 Laminated FRP composite made cylindrical shell with simulated internal cracks.

\section{Results and Discussion}

\subsection{Effect of cracks on fundamental frequency of vibration}

Fundamental frequency of vibration of the composite cylindrical shell along with edge or internal cracks of similar sizes, considered at locations close to the clamped edge have been compared with the natural frequency of the structure in absence of defects in Table 3. It has been clearly revealed that, cracks reduce the fundamental frequency of vibration to a great extent. This is in accordance with the physics that cracks in the structure add flexibility hence reducing the rigidity of the structure leading to a low fundamental frequency of vibration. Frequencies of both the edge and internal cracked cylindrical shells have been found to be in close range (Table 3). However, magnitude of the frequencies reveals that, fundamental frequency of vibration of edge-cracked composite shell is comparatively less as compared to the shell structures with internally located cracks. Hence, internally-cracked shell structures are comparatively stiffer than the edge-cracked composite shell structures.

Table 3 Fundamental frequencies of cantilevered laminated composite shells with and without cracks

\begin{tabular}{|l|l|l|l|}
\hline Shell Type & $\begin{array}{l}\text { Without } \\
\text { crack }(\mathrm{Hz})\end{array}$ & $\begin{array}{l}\text { Edge } \\
\text { cracked } \\
(\mathrm{Hz})\end{array}$ & $\begin{array}{l}\text { Internal } \\
\text { cracked } \\
(\mathrm{Hz})\end{array}$ \\
\hline $\begin{array}{l}\text { Cantilevered } \\
\text { cylindrical shell }\end{array}$ & 0.17552 & 0.12859 & 0.12880 \\
\hline
\end{tabular}


4.2. Effect of change of position of edge cracks on fundamental frequency of vibration

The laminated FRP composite made cylindrical shell has been analyzed for different edge cracks with position varying from the clamped to the free edge $\left(\mathrm{x}_{\mathrm{c}}\right)$. The fundamental frequency of vibration has been observed to be increasing almost linearly for edge cracks lying in between the clamped edge, $x_{c}=0$ up to $x_{c}=2100 \mathrm{~mm}$ (zone-I) as shown in Figure 4. For $2100 \mathrm{~mm} \leq \mathrm{x}_{\mathrm{c}} \leq 3600$ $\mathrm{mm}$ (zone-II), the fundamental frequency of vibration has been observed to be increasing in a non-linear manner. However, beyond $3600 \mathrm{~mm}$ (zone-III) the fundamental frequency of vibration has been observed to be stabilized at a frequency of $0.1285 \mathrm{~Hz}$. Hence, it can be concluded that edge cracks towards the free end (zone-III) of the cylindrical shell are safe for the structure as they partially reduce the frequency of vibration as compared to the edge cracks towards the clamped edge (zone-I).

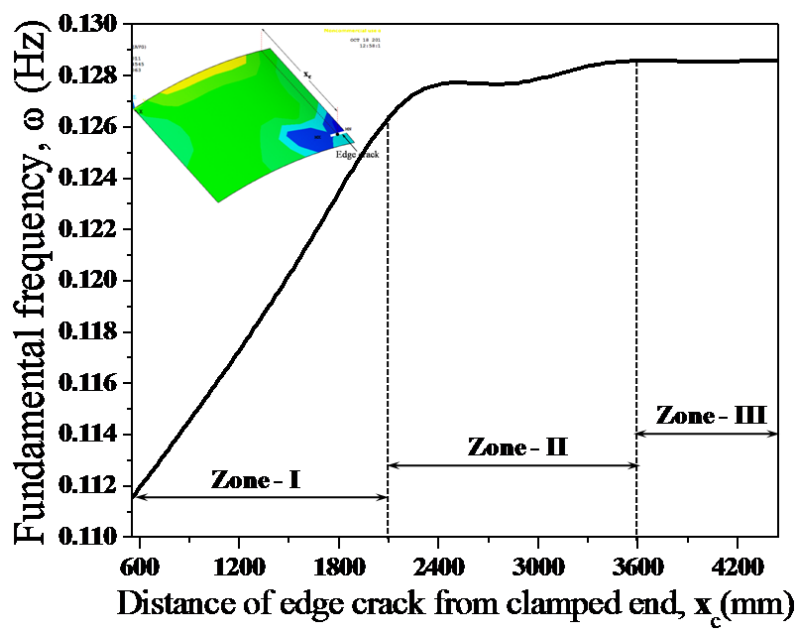

Fig.4 Effect of edge cracks on fundamental frequency of the cantilevered laminated cylindrical shell, as the crack position is changed from the clamped to the free edge.

\subsection{Effect of change of position of internal cracks on fundamental frequency of vibration}

Internal cracks of similar sizes considered at different locations $\left(x_{c}\right)$ from the clamped to the free edge of the cantilevered composite cylindrical shell have been observed to be to be increasing the natural frequency in a non-linear fashion throughout the domain. A minute observation of the plot shown in Figure 5 reveals that, for internal cracks close to the clamped edge $\left(0 \leq \mathrm{x}_{\mathrm{c}} \leq 900\right.$ $\mathrm{mm}$ ) fundamental frequency is reduced. However, beyond this point up till the free edge the frequency of oscillation has been seen to be increased and finally stabilized towards the free edge of the shell. These results can still be realized better through the comparison plot shown in Figure 6. For similar positions and dimensions internal cracks add more geometrical non-linearity to the composite shell structure as compared to the edge-cracks which leads to the non-linear behavior of the fundamental frequency as represented in the Figure 5.

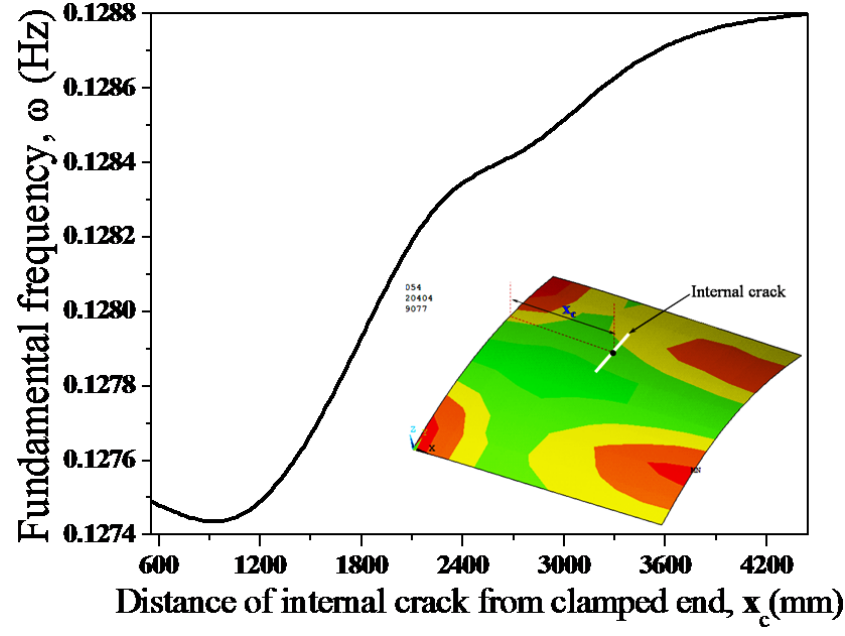

Fig.5 Effect of internal cracks on fundamental frequency of the cantilevered laminated cylindrical shell, as the crack position is changed from the clamped to the free edge.

\subsection{Effect of edge or internal cracks on fundamental frequency of vibration}

Effect of edge cracks or internal cracks in the cantilevered laminated FRP composite made cylindrical shells have been compared individually in the Figure 6. It can be clearly observed from Figure 6 that, frequency of vibration of the shell structure is comparatively higher along with the internal cracks than the edge cracks.

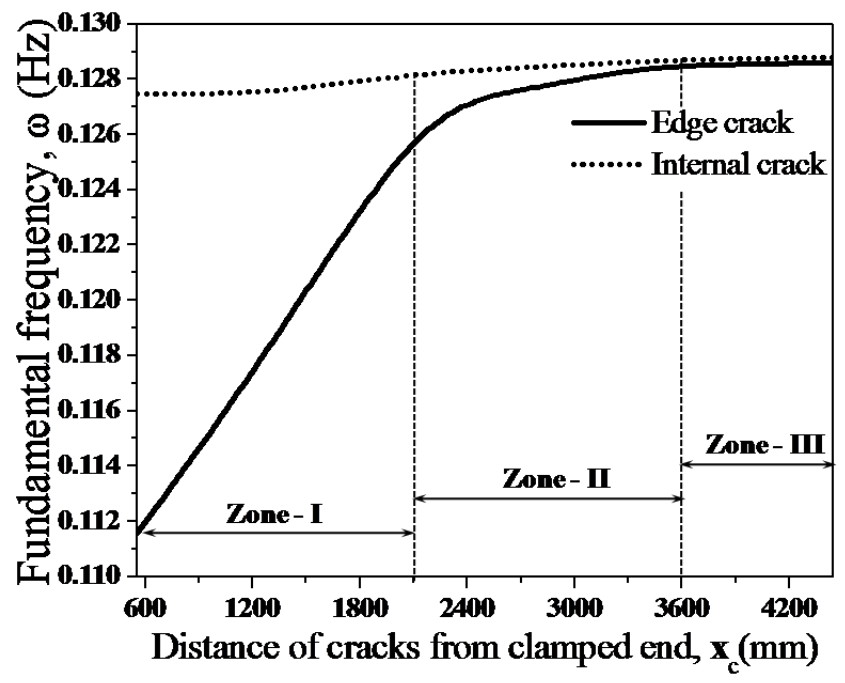

Fig.6 Effect of edge or internal cracks on fundamental frequency of the cantilevered laminated cylindrical shell.

This reveals that, the internal cracks are comparatively safe for the shell structure as compared to the edge cracks in the zones I and II. However, in the zone-III, i.e., towards the free edge of the cantilevered composite cylindrical shell both the edge and internal cracks have almost similar effects in terms of effect on the fundamental frequency of vibration. Hence, this zone may be treated as a neutral zone as cracks lying in this zone 
have marginal effect on the fundamental frequency of vibration of the composite shell structures.

\section{Summary and conclusions}

Laminated FRP composite made cracked cylindrical shell structures have been analyzed through a three dimensional FEM based fracture model developed in the present study. The model provides sufficient scope for studying the effect of edge and internal cracks on the fundamental frequency of vibration of the laminated cylindrical shell structure. Some of the major conclusions of the present analyses are:

1) Internally-cracked composite cylindrical shell structures are comparatively stiffer than the edgecracked composite shell structures for similar crack size and crack positions.

2) Natural frequency of vibration of composite cylindrical shell structures are marginally affected when the cracks are positioned towards the free edge.

3) Interlaminar cracks positioned closer to the clamped edge tremendously affect the frequency of free vibration hence, reducing the stiffness of the composite shell structures.

4) Internally-cracked composite cylindrical shell structures have more geometrical non-linearity as compared to the edge-cracked shell structures.

5) Interlaminar cracks lying within the neutral zone (zone-III, $3600 \mathrm{~mm} \leq \mathrm{x}_{\mathrm{c}} \leq 5000 \mathrm{~mm}$ ), towards the free edge of the cantilevered composite cylindrical shell have negligible effect on the fundamental frequency of vibration of the laminated FRP composite made cylindrical shell structures.

\section{Acknowledgement}

The authors are thankful to the All India Council for technical Education (AICTE), New Delhi for sponsoring the above research through a project grant Ref: 8023/RID/RPS/56/11/12, dated 26 ${ }^{\text {th }}$ March, 2012.

\section{References}

J. N. Reddy, (1984) Exact solutions of moderately thick laminated shells, Journal of Engineering Mechanics Division, Proceedings of the American Society of Civil Engineers, vol.110, pp.794-809.
K. Chandrashekhara, (1989) Free vibrations of anisotropic laminated doubly curved shells, Computers and Structures, vol.33, pp.435-440.

M. S. Qatu, A. W. Leissa, (1991) Free vibrations of completely free doubly curved laminated composite shallow shells, Journal of Sound and Vibration, vol.151, pp.9-29.

K. P. Soldatos, (1991) A refined laminated plate and shell theory with applications, Journal of Sound and Vibration, vol.144, pp.109-129.

Nosier, J. N. Reddy, (1992) Vibration and stability analyses of cross-ply laminated circular cylindrical shells, Journal of Sound and Vibration, vol.157, pp.139-159.

H. E. Williams , (1992) On the free vibration of thin cylindrical shells with large circumferential wave number: Rayleigh's solution, Journal of Sound and Vibration, vol.157, pp. 277288.

M. Ambii, (2011) Nonlinear vibrations of laminated circular cylindrical shells: comparison of different shell theories, Composite Structures, vol.94, pp.207-220.

M. Ambii, (2012) Nonlinear vibrations of angle-ply laminated circular cylindrical shells: Skewed modes, Composite Structures, vol.94, pp.3696-3709.

Y. Chen, G. Jin n, Z. Liu, (2013) Free vibration analysis of circular cylindrical shell with non-uniform elastic boundary constraints, International journal of Mechanical Sciences, vol. 74, pp. $120-132$

E. Assan, M.H. Aliabadi, (1993) Analysis of cracked cylindrical shells by a strain-based finite element, Advances in Engineering Software, vol.17, pp.39-47.

S. Yang, W. Chen, (1996) Free vibration analysis of patched cracked composite laminates using a multilayer hybrid-stress finite element method, Engineering Fracture Mechanics, vol.54, Iss.4, pp.557-568

M. Javidruzi, A. Vafai, J.F. Chen, J.C. Chilton, (2004) Vibration, buckling and dynamic stability of cracked cylindrical shells, Thin-walled structures, vol. 42, pp. 79-99

Y.T. Kim , B. Haghpanah, R. Ghosh, H. Ali b, A.M.S Hamouda, A . Vaziri (2013) Instability of a cracked cylindrical shell reinforced by an elastic liner, Thin-walled structures, vol. 70, pp. 39-48

H. Allahbakhsh, M. Shariati, (2014) Instability of cracked CFRP Composite cylindrical shells under combined loading, Thinwalled structures, vol. 74, pp. 28-35.

J.R. Rice, (1968) A Path dependent Integral and the approximate analysis of stress concentration by notches and cracks, Engineering Fracture Mechanics, vol.35, pp.379-86. 